\title{
Oxygen Vacancy and Chemical Ordering Control Oxygen Evolution Activity of $\mathrm{Sr}_{2-x} \mathrm{Ca}_{x} \mathrm{Fe}_{2} \mathrm{O}_{6-\delta}$ Perovskites
}

Charles Bloed, ${ }^{\ddagger a}$ Jiam Vuong, ${ }^{\ddagger a}$ Alexis Enriquez, ${ }^{a}$ Sharan Raghavan, ${ }^{a}$ Ich Tran, ${ }^{\mathrm{b}}$ Shahab Derakhshan, ${ }^{\mathrm{a}}$ and Hadi Tavassol*a

a Department of Chemistry and Biochemistry, California State University, Long Beach, Long Beach, CA, United States, 90840

bIrvine Materials Research Institute (IMRI), University of California, Irvine, Irvine, CA, United States, 92697

\section{Supporting Information}

Email: hadi.tavassol@ csulb.edu 


\section{Methods}

Synthesis

The synthesis of $\mathrm{Sr}_{2-\mathrm{x}} \mathrm{Ca}_{\mathrm{x}} \mathrm{Fe}_{2} \mathrm{O}_{6-\delta}(\mathrm{x}=0,0.25,0.50,0.75,1.00,1.25,1.50,1.75,2.00)$ follow conventional solid-state synthesis. First, the stoichiometric mixtures of the $\mathrm{CaCO}_{3}$ (Alfa Aesar), $\mathrm{SrCO}_{3}$ (Alfa Aesar), and $\mathrm{Fe}_{2} \mathrm{O}_{3}$ (Alfa Aesar) are grounded, mixed and pelletized. The platinum sheets were placed in between the pellets and the alumina boats. Next, the samples were heated at $1250^{\circ} \mathrm{C}$ for $48 \mathrm{hrs}$ in argon atmosphere. Also, the synthesis was repeated in air. The cooling and heating rate were at $100^{\circ} \mathrm{C} / \mathrm{hrs}$ for both. Repeated grinding and heating were performed to achieve single phase.

\section{X-Ray Diffraction}

The crystal structure and the purity of the sample is determined by powder X-ray diffraction data collected using PANalytical X'Pert Pro MPD diffractometer, equipped with a linear X'Celerator detector, $\mathrm{Cu} \mathrm{Ka} 1$ radiation and Settings.

Electrochemistry:

Synthesized powders were made into an ink with the composition of $8 \mathrm{mg}$ of oxide material, $2 \mathrm{mg}$ of Ketjen Black EC-600JD carbon, $4 \mathrm{~mL}$ of 95\% ethanol, and $200 \mu \mathrm{l}$ of Nafion (Sigma Aldrich). The mixture was sonicated for 1.5 hours. $5 \mu$ of the slurry was drop casted on to the glassy carbon electrode and allowed to dry overnight.

Cyclic voltammetry experiments were performed in three electrode cell using a Pt wire counter electrode and a $\mathrm{Ag} / \mathrm{AgCl}$ reference electrode. Before each experiment, potential of the $\mathrm{Ag} / \mathrm{AgCl}$ reference electrode was measured vs. a Pt wire while purging with $\mathrm{H}_{2}(\mathrm{~g})$. This value was used for reporting the potential vs. RHE. A $0.1 \mathrm{M} \mathrm{KOH}$ solution was used as the electrolyte and was purged with $\mathrm{O}_{2}$ prior the electrochemical measurement. Data reported here was from the third electrochemical cycle across all samples. All experiments were performed using a $\mathrm{CH}$ Instruments potentiostat and rotation was performed using a Pine Research rotator. Rotating disk electrode measurements were performed in $\mathrm{O}_{2}$ saturated $0.1 \mathrm{M} \mathrm{KOH}$ solutions at $1600 \mathrm{rpm}$.

X-ray photoelectron spectroscopy (XPS):

X-ray photoelectron spectroscopy was performed on a Kratos AXIS-Supra spectrometer, equipped with a monochromatic Al K- $\alpha$ X-ray source. For each sample, survey spectrum was acquired using $1 \mathrm{eV}$ energy step with $100 \mathrm{~ms}$ dwell time and a pass energy of $80 \mathrm{eV}$. Detail spectra of Fe 2p. Ca $2 \mathrm{p}, \mathrm{Sr} 3 \mathrm{~d}, \mathrm{O} 1 \mathrm{~s}$ and $\mathrm{C} 1 \mathrm{~s}$ were averaged over 3 scans with $0.1 \mathrm{eV}$ energy step, $100 \mathrm{~ms}$ dwell time and a pass energy of $20 \mathrm{eV}$. C 1s spectra was used as an internal reference and binding energy values were adjusted with respect to this peak.

\section{Structural details:}

Table S1 lists the structural properties of compounds synthesized here. 
Table S1. Crystal structure and lattice parameters of brownmillerite and perovskites a) air synthesized b) argon synthesized.

a)

\begin{tabular}{|l|l|l|l|l|l|}
\hline Compound & $\begin{array}{l}\text { Space } \\
\text { Group }\end{array}$ & $\mathrm{a}(\AA)$ & $\mathrm{b}(\AA)$ & $\mathrm{c}(\AA)$ & Volume $\left(\AA^{3}\right)$ \\
\hline $\mathrm{Ca}_{2} \mathrm{Fe}_{2} \mathrm{O}_{6-\delta}$ & Pnma & $5.4272(3)$ & $14.7607(8)$ & $5.5964(3)$ & 448.32 \\
\hline $\mathrm{Sr}_{0.25} \mathrm{Ca}_{1.75} \mathrm{Fe}_{2} \mathrm{O}_{6-\delta}$ & Pnma & $5.437(1)$ & $14.857(3)$ & $5.613(1)$ & 453.41 \\
\hline $\mathrm{Sr}_{0.50} \mathrm{Ca}_{1.50} \mathrm{Fe}_{2} \mathrm{O}_{6-\delta}$ & Pnma & $5.4496(9)$ & $14.9380(2)$ & $5.613(1)$ & 457.57 \\
\hline $\mathrm{Sr}_{0.75} \mathrm{Ca}_{1.25} \mathrm{Fe}_{2} \mathrm{O}_{6-\delta} * *$ & Pnma & $5.452(1)$ & $14.960(2)$ & $5.6214(8)$ & 458.45 \\
\hline $\mathrm{SrCaFe}_{2} \mathrm{O}_{6-\delta}$ & Ibm2 & $5.599(5)$ & $15.130(1)$ & $5.536(7)$ & 469.03 \\
\hline $\mathrm{Sr}_{1.25} \mathrm{Ca}_{0.75} \mathrm{Fe}_{2} \mathrm{O}_{6-\delta} *$ & & & & & \\
\hline $\mathrm{Sr}_{1.50} \mathrm{Ca}_{0.50} \mathrm{Fe}_{2} \mathrm{O}_{6-\delta}$ & I4/mmm & $10.9302(8)$ & $10.9302(8)$ & $7.7288(0)$ & 923.37 \\
\hline $\mathrm{Sr}_{1.75} \mathrm{Ca}_{0.25} \mathrm{Fe}_{2} \mathrm{O}_{6-\delta}$ & I4/mmm & $10.9375(2)$ & $10.9375(2)$ & $7.7339(9)$ & 925.21 \\
\hline $\mathrm{Sr}_{2} \mathrm{Fe}_{2} \mathrm{O}_{6-\delta}$ & $\mathrm{I} / \mathrm{mmm}$ & $10.9540(1)$ & $10.9540(1)$ & $7.7456(6)$ & 929.40 \\
\hline
\end{tabular}

*Phase transition occurred.

** Phase impurity

b)

\begin{tabular}{|l|l|l|l|l|l|}
\hline Compound & Space Group & a $(\AA)$ & b $(\AA)$ & c $(\AA)$ & Volume $\left(\AA^{3}\right)$ \\
\hline $\mathrm{Ca}_{2} \mathrm{Fe}_{2} \mathrm{O}_{6-\delta}$ & Pnma & $5.4260(3)$ & $14.7598(7)$ & $5.5973(2)$ & 448.27 \\
\hline $\mathrm{Sr}_{0.25} \mathrm{Ca}_{1.75} \mathrm{Fe}_{2} \mathrm{O}_{6-\delta}$ & Pnma & $5.438(1)$ & $14.861(3)$ & $5.6138(9)$ & 453.62 \\
\hline $\mathrm{Sr}_{0.50} \mathrm{Ca}_{1.50} \mathrm{Fe}_{2} \mathrm{O}_{6-\delta}$ & Pnma & $5.4508(6)$ & $14.954(2)$ & $5.6208(5)$ & 458.15 \\
\hline $\mathrm{Sr}_{0.75} \mathrm{Ca}_{1.25} \mathrm{Fe}_{2} \mathrm{O}_{6-\delta}$ & Pnma & $5.456(2)$ & $15.034(8)$ & $5.623(2)$ & 461.30 \\
\hline $\mathrm{SrCaFe}_{2} \mathrm{O}_{6-\delta} * *$ & Ibm2 & $5.636(3)$ & $15.129(6)$ & $5.474(2)$ & 466.75 \\
\hline $\mathrm{Sr}_{1.25} \mathrm{Ca}_{0.75} \mathrm{Fe}_{2} \mathrm{O}_{6-\delta}$ & Ibm2 & $5.633(3)$ & $15.30(1)$ & $5.492(4)$ & 473.33 \\
\hline $\mathrm{Sr}_{1.50} \mathrm{Ca}_{0.50} \mathrm{Fe}_{2} \mathrm{O}_{6-\delta}$ & Ibm2 & $5.650(4)$ & $15.47(1)$ & $5.500(5)$ & 480.81 \\
\hline $\mathrm{Sr}_{1.75} \mathrm{Ca}_{0.25} \mathrm{Fe}_{2} \mathrm{O}_{6-\delta}$ & Imcm & $5.659(3)$ & $15.565(7)$ & $5.522(3)$ & 486.38 \\
\hline $\mathrm{Sr}_{2} \mathrm{Fe}_{2} \mathrm{O}_{6-\delta}$ & Imcm & $5.676(2)$ & $15.646(6)$ & $5.541(2)$ & 492.10 \\
\hline
\end{tabular}

**Phase impurity 
Structural details of the compounds in the $2 \theta=25^{\circ}-52^{\circ}$ region (Fig. S1). Figure also shows the shift to lower angles as $\mathrm{Sr}$ content increases in the structures.

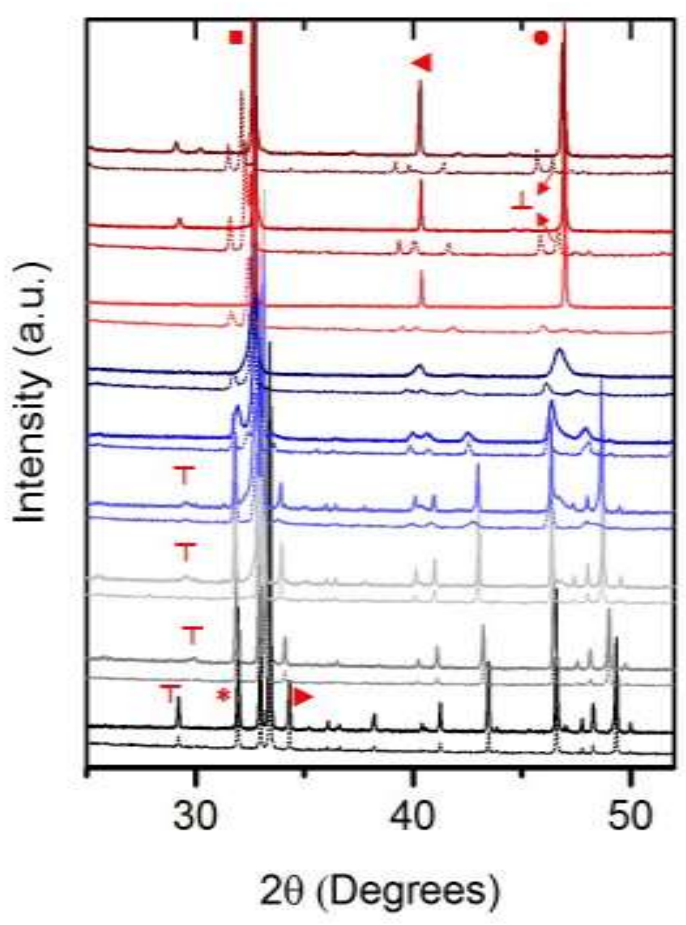

Fig. S1 X-ray diffraction spectroscopy of air-synthesized (top) and Ar-synthesized (bottom) compounds with the general formula of $\mathrm{Sr}_{2-\mathrm{x}} \mathrm{Ca}_{\mathrm{x}} \mathrm{Fe}_{2} \mathrm{O}_{6-\delta} . \mathrm{x}$ increases from $\mathrm{x}=0$ at the top the bottom $(\mathrm{x}=2)$. $(222), \bullet(440),(622)$ are present in perovskite type structures. $\mathrm{T}(131)$ is present in Pnma and $\perp$ (222) Imcm in space groups. (051) and *(002) are also shown.

\section{XPS fitting:}

Spectra are acquired from the compounds synthesized in the $\mathrm{Sr}_{2-\mathrm{x}} \mathrm{Ca}_{\mathrm{x}} \mathrm{Fe}_{2} \mathrm{O}_{6-\delta}$ system. XPS fitting of the oxygen (O 1s) and iron (Fe 2p) were performed using numerical convolution of a Lorentzian with a Gaussian (superset of Voigt functions) on Shirley backgrounds. Oxygen $1 s$ region shows three main features represented in red, blue and green. Fig. S2 shows the fits of the O $1 s$ region. 


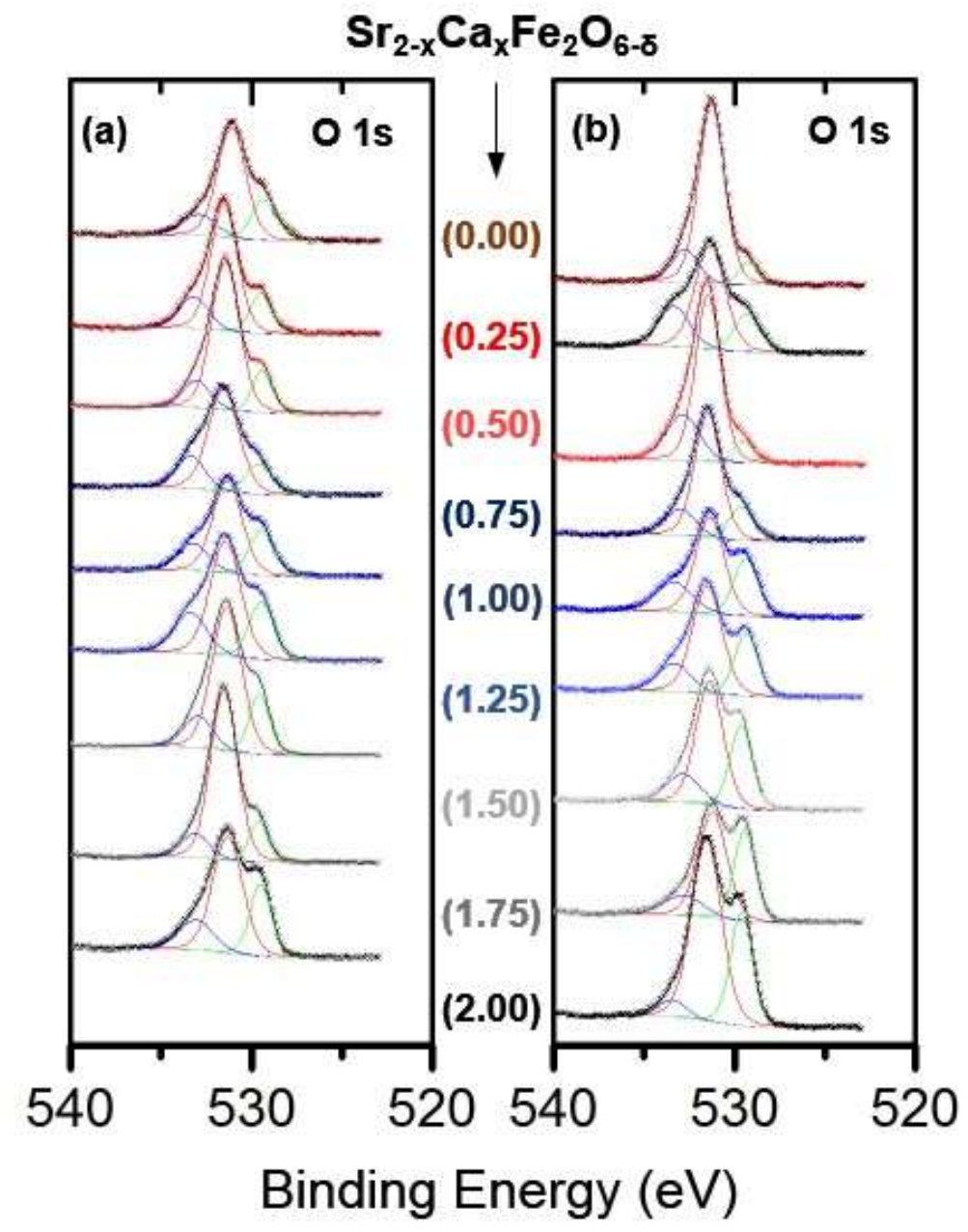

Fig. S2 X-ray photoelectron spectroscopy measurement results of the samples synthesized (a) under air and (b) under Ar. The oxygen 1s region is fitted and shows three main features.

The area under the peaks of the $\mathrm{Fe} 2 \mathrm{p}_{3 / 2}$ region were used to calculate the amount of oxygen vacancies present in these compounds. XPS spectra have been employed to quantify surface concentrations. ${ }^{1-3}$ XPS spectra with the high and low binding energy features shown in blue and red are presented in the Fig. 2 in the main text. The area under these peaks were used for deriving $\delta$ in $\mathrm{Sr}_{2-\mathrm{x}} \mathrm{Ca}_{\mathrm{x}} \mathrm{Fe}_{2} \mathrm{O}_{6-\delta}$, by quantifying the area under the peak of the features corresponding to the $\mathrm{Fe}^{3+}$ and $\mathrm{Fe}^{4+}$ for the low (red) and high (blue) binding energies respectively. We followed a methodology established for fitting the XPS spectra of the first row transition metals, and their oxides. ${ }^{3}$ To acquire a more accurate measure of surface concentration, positions of the high and low binding energy features were fixed. For this analysis, fitting was performed simultaneously on the of $\mathrm{Fe} 2 \mathrm{p}_{3 / 2}$ spectra with constrains put on position and peak shape (FWHM=0.2-3), leaving peak area as the only variant in determining the relative concentration of high and low binding energy features. Line shapes based on a superset of Voigt functions on Shirley backgrounds were used. 


\section{Polarization curves:}

Fig. S3 shows representative polarization curves of samples synthesized and tested in this study.

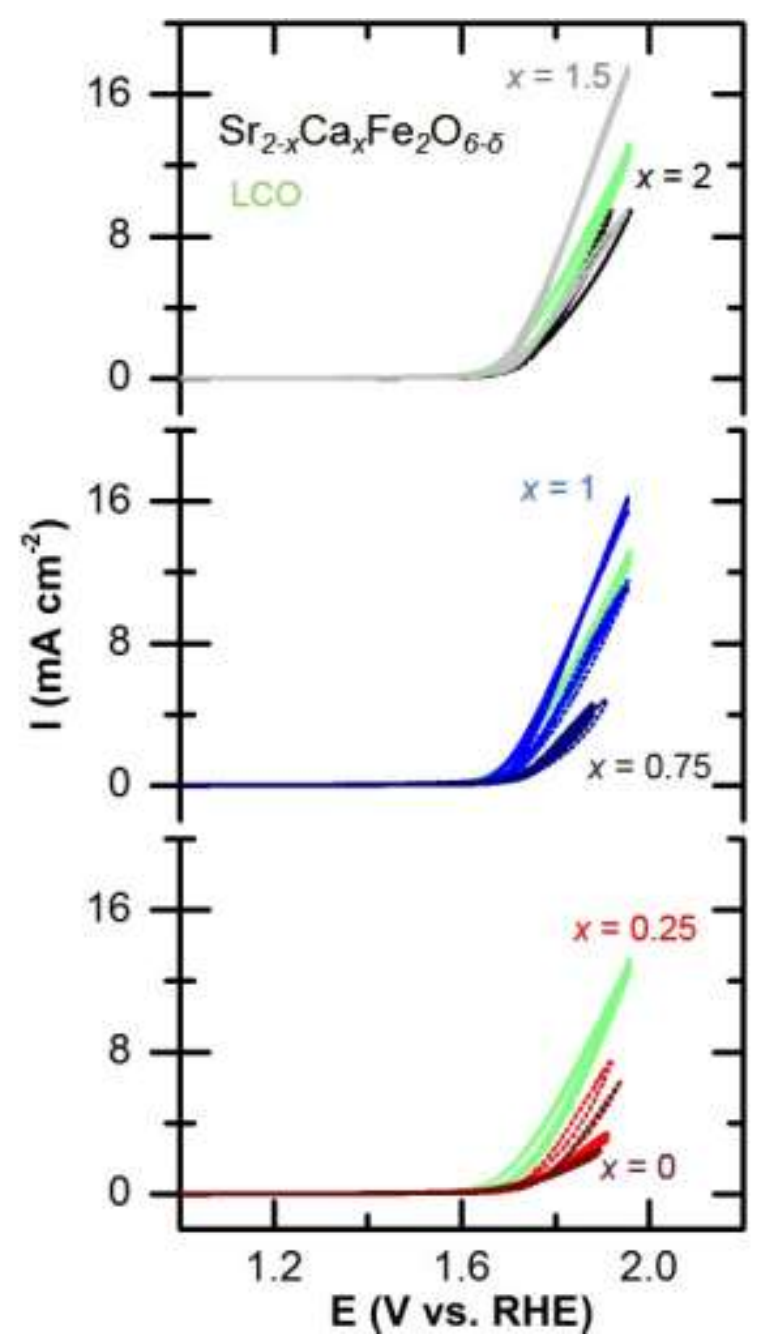

Fig. S3 Cyclic voltammetry analysis of the materials synthesized and tested in this study.

3 shows the longer-term polarization curves of samples, showing higher degradation in $\mathrm{Ca}_{2} \mathrm{Fe}_{2} \mathrm{O}_{6-\delta}$ and $\mathrm{Sr}_{2} \mathrm{Fe}_{2} \mathrm{O}_{6-\delta}$ compared to the samples with mixed A-site composition, e.g. $\mathrm{Sr}_{0.25} \mathrm{Ca}_{1.75} \mathrm{Fe}_{2} \mathrm{O}_{6-\delta}$ and $\mathrm{Sr}_{0.75} \mathrm{Ca}_{1.25} \mathrm{Fe}_{2} \mathrm{O}_{6-\delta}$. There are other closely related compounds including $\mathrm{Ca}_{2} \mathrm{Mn}_{2} \mathrm{O}_{5}, \mathrm{Ca}_{2} \mathrm{Fe}_{(1-x)} \mathrm{Co}_{\mathrm{x}} \mathrm{O}_{5}$, and $\mathrm{N}$-doped oxygen deficient $\mathrm{Ca}_{2} \mathrm{Fe}_{2} \mathrm{O}_{5}$ which have been studied for oxygen reactions. ${ }^{4-7}$ 

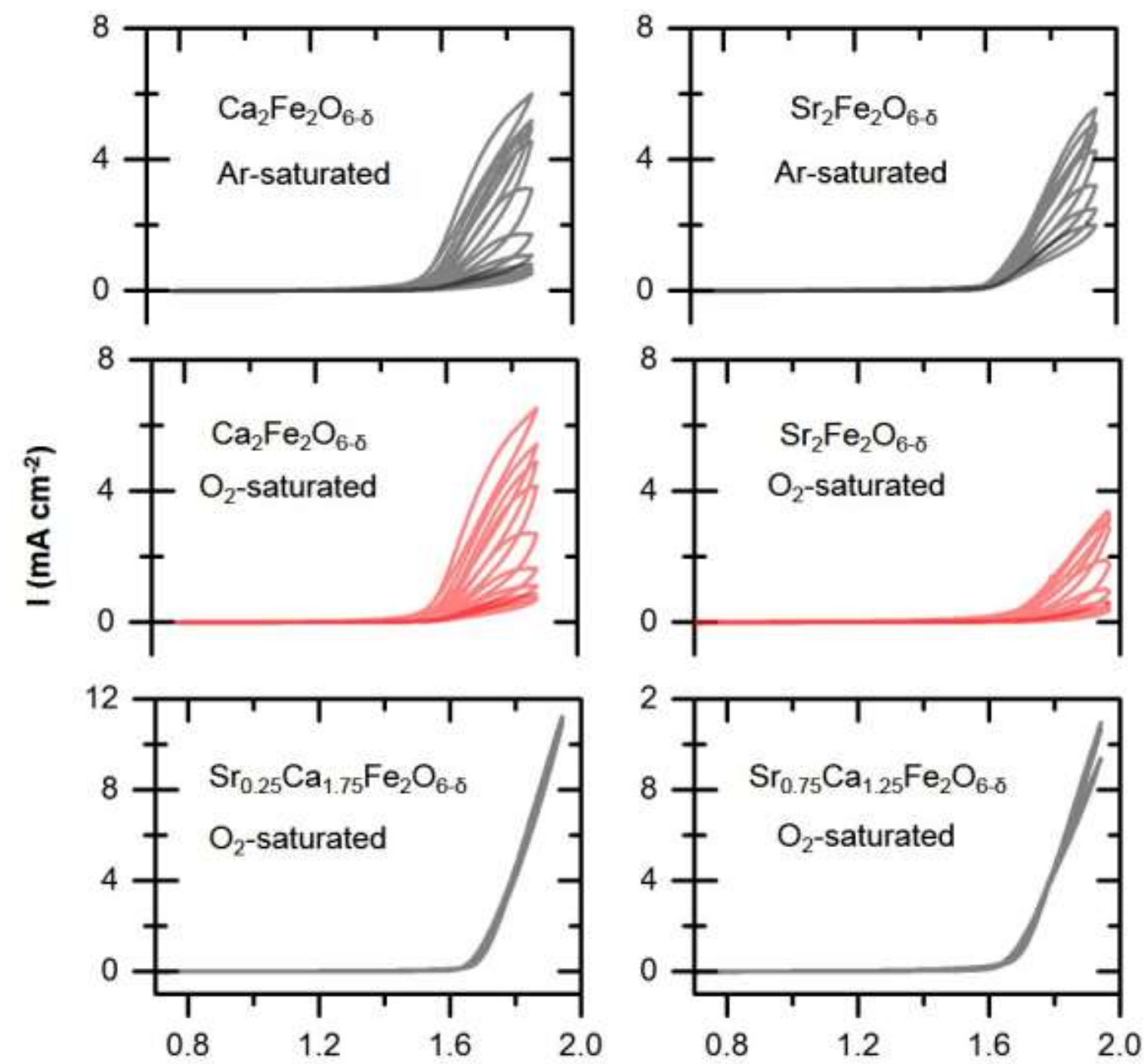

E (V vs. RHE)

Fig. S4 Longer-term polarization curves of a subset of samples in the Ar-synthesized $\mathrm{Sr}_{2-\mathrm{x}} \mathrm{Ca}_{\mathrm{x}} \mathrm{Fe}_{2} \mathrm{O}_{6-\delta}$. Electrochemical measurements were performed under indicated environments between $0.7 \mathrm{~V}$ to $1.9 \mathrm{~V}$ vs. RHE for 10 consecutive cycles.

\section{References:}

1. Kodintsev, I. M.; Trasatti, S.; Rubel, M.; Wieckowski, A.; Kaufher, N., X-ray photoelectron spectroscopy and electrochemical surface characterization of iridium(IV) oxide + ruthenium(IV) oxide electrodes. Langmuir 1992, 8 (1), $283-290$. 2. Rochefort, D.; Dabo, P.; Guay, D.; Sherwood, P. M. A., XPS investigations of thermally prepared RuO2 electrodes in reductive conditions. Electrochimica Acta 2003, 48 (28), 4245-4252.

3. Biesinger, M. C.; Payne, B. P.; Grosvenor, A. P.; Lau, L. W. M.; Gerson, A. R.; Smart, R. S. C., Resolving surface chemical states in XPS analysis of first row transition metals, oxides and hydroxides: $\mathrm{Cr}, \mathrm{Mn}, \mathrm{Fe}, \mathrm{Co}$ and Ni. Applied Surface Science 2011, 257 (7), 2717-2730.

4. Thundiyil, S.; Kurungot, S.; Devi, R. N., Bifunctional Oxygen Reduction and Evolution Activity in Brownmillerites Ca2Fe(1-x)CoxO5. ACS Omega 2019, 4 (1), 31-38. 
5. Tsuji, E.; Motohashi, T.; Noda, H.; Kowalski, D.; Aoki, Y.; Tanida, H.; Niikura, J.; Koyama, Y.; Mori, M.; Arai, H.; loroi, T.; Fujiwara, N.; Uchimoto, Y.; Ogumi, Z.; Habazaki, H., Brownmillerite-type Ca2FeCoO5 as a Practicable Oxygen Evolution Reaction Catalyst. ChemSusChem 2017, 10 (14), 2864-2868.

6. Jijil, C. P.; Lokanathan, M.; Chithiravel, S.; Nayak, C.; Bhattacharyya, D.; Jha, S. N.; Babu, P. D.; Kakade, B.; Devi, R. N., Nitrogen Doping in Oxygen-Deficient Ca2Fe2O5: A Strategy for Efficient Oxygen Reduction Oxide Catalysts. ACS Appl. Mater. Interfaces 2016, 8 (50), 34387-34395.

7. Kim, J.; Yin, X.; Tsao, K.-C.; Fang, S.; Yang, H., Ca2Mn2O5 as Oxygen-Deficient Perovskite Electrocatalyst for Oxygen Evolution Reaction. J. Am. Chem. Soc. 2014, 136 (42), 14646-14649. 